\title{
The death receptor TRAIL in cancer cell apoptosis
}

\author{
Norihisa Ishimura and Gregory J. Gores \\ Division of Gastroenterology and Hepatology, Mayo Clinic, College of Medicine, Rochester, MN 55905
}

\begin{abstract}
Abbreviations: cellular FADD-like interleukin-1 $\beta$-converting enzyme inhibitory protein; cFLIP, deathinducing signaling complex; DISC, death receptor; DR, Fas-associated death domain; FADD, Fas ligand; Fas-L, receptor-interacting protein; RIP, inhibitor of apoptosis protein; IAP, IКB kinase; IKK, c-Jun $\mathrm{N}$-terminal kinase; JNK, mitogen activated protein; MAP, NF- $\kappa \mathrm{B}$-inducing kinase; NIK, tumor necrosis factor; TNF, TNFR-associated protein with death domain; TRADD, TNF-related apoptosis-inducing ligand; TRAIL.
\end{abstract}

\begin{abstract}
Apoptosis is a key regulator or tissue homeostasis. Death ligands and death receptors of the tumor necrosis factor (TNF) family play crucial roles in mediating apoptosis. TNF-related apoptosis-inducing ligand (TRAIL) is unique amongst death ligands in that it uniquely induces apoptosis in transformed cells, but not normal cells. Indeed, TRAIL is being developed as an anticancer therapy. However, many malignant tumors are resistant to apoptosis induction by TRAIL. Understanding the mechanism of resistance to TRAIL-mediated apoptosis will not only provide insight regarding transduction of the death signal, but will also be essential for designing strategies to overcome resistance to TRAIL for clinical applicatons. In this review, we focus on the apoptosis signaling pathways stimulated by TRAIL, and summarize recent clues regarding TRAIL physiology.
\end{abstract}

Key Words: Death receptor, Fas, TNF- $\alpha$, TRAIL, cancer, apoptosis

(Received November 24, 2004; Accepted February 7, 2005)

\section{Introduction}

Cell death may occur by three major recognized morphologic phenotypes, oncotic necrosis, autophagy, and apoptosis, the latter also known as programmed cell death. Apoptosis occurs in various physiologic and pathologic situations and has an important regulatory function in tissue homeostasis and immune regulation ${ }^{1)}$. In principle, there are two alternative pathways that initiate apoptosis: one is mediated by death receptors on the cell surface (referred to as the 'extrinsic pathway'); the other is mediated by mitochondria (referred to as the "intrinsic pathway' $)^{2,3}$. In both pathways, caspases, cysteine aspartyl-specific proteases are activated and cleave cellular substrates; it is caspase activation which leads to the biochemical and morphological changes characteristic of apoptosis ${ }^{4)}$. Apoptosis pathways are tightly controlled by a number of inhibitory and promoting factors ${ }^{5}$. Defects in the apoptosis inducing pathways can eventually lead to expansion of a population of neoplastic cells. Resistance

Correspondence to: Gregory J. Gores, MD, Professor of Medicine, Mayo Clinic College of Medicine, 200 First Street SW, Rochester, Minnesota 55905, Tel: 507-284-0686, Fax: 507-284-0762, E-mail: gores.gregory@mayo.edu to apoptosis can also augment the escape of tumor cells from surveillance by the immune system. Moreover, because chemotherapy and irradiation act primarily by inducing apoptosis, defects in the apoptotic pathway produce cancer cells resistant to therapy. Therefore, an understanding of the molecular events that regulate apoptosis and how cancer cells evade apoptosis may provide new opportunities for pathway based rational anticancer therapy.

In this article, we provide an overview of death receptor pathways and their referrence to cancer cell apoptosis. We also discuss recent clues to the physiological role of TRAIL, and explain the scientific rational for its further study as an anticancer agent.

\section{Death receptors and ligands}

Death receptors are members of the tumor necrosis growth factor (TNF) receptor gene superfamily, which consists of more than 20 proteins with a broad range of biological functions including the regulation of cell death and survival, differentiation or immune regulation $^{6,7)}$. Death receptors trigger apoptosis after binding with cognate ligands or in experimental conditions, 
agonistic antibodies ${ }^{8,9)}$. Death receptors are type-I transmembrane proteins with a C-terminal intracellular tail, a membrane-spanning region, and an extracellular ligandbinding region containing 1-5 cysteine-rich domains, and a cytoplasmic domain of about 80 amino acids called 'the death domain'. The death domain is essential for transmitting the death signals from the cell surface to intracellular signaling pathways. To date, the well characterized death receptors comprise Fas (CD95/ APO-1), TNF receptor 1 (TNFR1), TNF-related apoptosis inducing ligand (TRAIL) receptor 1 [TRAIL-R1, also referred to as death receptor 4 (DR4)], TRAIL receptor 2 (TRAIL-R2, also referred to as DR5/ Killer/ TRICK2].

The corresponding ligands of TNF superfamily comprise death receptor ligands such as Fas ligand (FasL), TNF $\alpha$, and TRAIL, which are type II transmembrane proteins, which may also exist as soluble molecules after cleavage by proteases present in the microenvironment. The cleavage forms can be biologically active.

\section{TRAIL and TRAIL receptors}

TRAIL was originally identified on the basis of sequence homology to FasL and other members of the TNF superfamily ${ }^{10)}$. This protein was independently discovered by another group of investigators and named Apo2 ${ }^{11)}$. TRAIL shares $28 \%$ amino acid (aa) sequence identity with FasL and $23 \%$ identity with TNF. TRAIL consists of 281 and 291 aa in the human and murine forms, respectively, which share $65 \%$ identity. TRAIL is expressed as a type II transmembrane protein ${ }^{12)}$, and its extracellular region can be cleaved proteolytically to release a biologically active soluble molecule. While TRAIL mRNA is constitutively expressed in a wide variety of normal tissues and tumors, the expression of functional TRAIL protein appears to be rather restricted to immune cells, including T cells, NK cells, monocytes, dendritic cells (DCs), and neutrophils ${ }^{13-15)}$, suggesting that the presence of TRAIL mRNA does not necessarily reflect functional protein expression due to posttranscriptional and/or post-translational regulation.

Like most other TNF family members, TRAIL binds to its membrane receptors as a homotrimer ${ }^{16)}$. So far, five human receptors specific for TRAIL have been identified (Fig. 1). TRAIL-R1 (DR4) ${ }^{17)}$ and TRAIL-R2 (DR5) ${ }^{18,19)}$ are the death receptors which contain a cytoplasmic death domain motif that are activated by TRAIL and transduce apoptotic signals. By contrast, two other receptors bind to TRAIL and appear to act as a 'decoy' (i.e. they bind the ligand but do not transmit signals). Decoy receptor (DcR)1 (TRAIL-R3) ${ }^{19,20)}$, which is a glycophospholipid (GPI)-linked molecule without an intracellular death domain, and DcR2 (TRAIL-R4) ${ }^{21,22)}$, which contains a truncated non-functional death domain, are unable to initiate apoptotic cell death although they have close homology to the extracellular domains of DR4 and DR5. Therefore, both receptors are incapable of transmitting an apoptosis signal. Although another TNF family receptor, osteoprotegerin $(\mathrm{OPG})^{23,24)}$, binds TRAIL with low affinity, this interaction appears to be of uncertain physiological significance. DcR1, DcR2, and OPG compete with DR4 and DR5 for TRAIL-binding and upon overexpression have been shown to inhibit TRAILinduced apoptosis.

In the mouse, only a single receptor resembling human DR4 and DR5 exists, along with two DcRs that are only distantly related by sequence homology to human DcR1 and DcR2, and one close homologue of OPG.

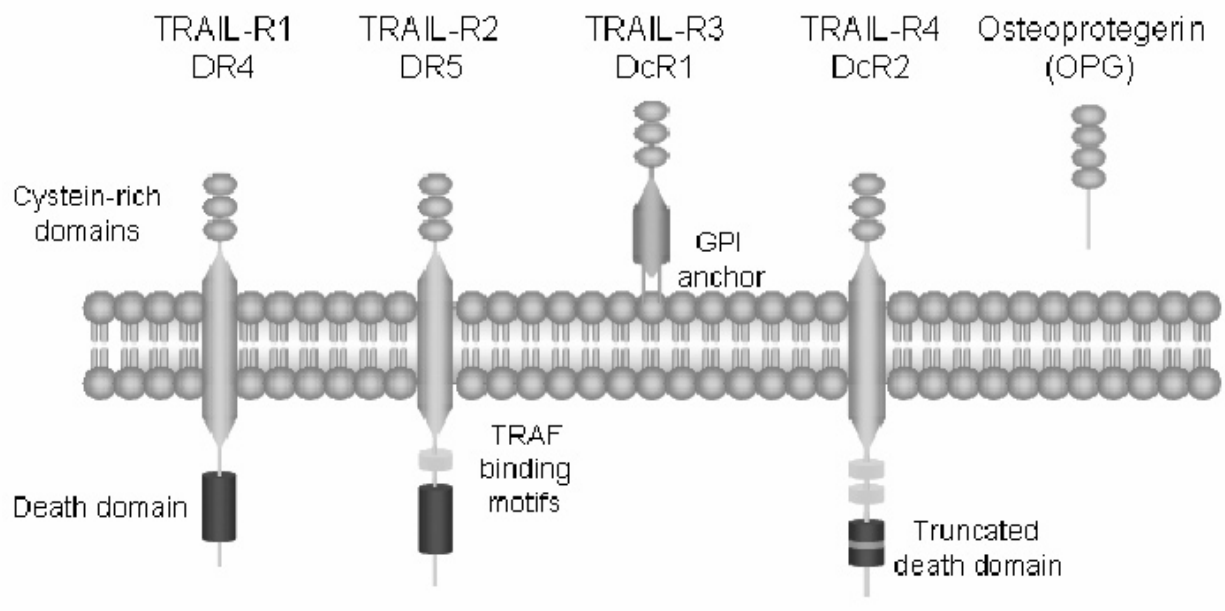

Fig. 1 Structures of human TRAIL receptors. TRAIL induces apoptosis via TRAIL-R1 (DR4) or TRAIL-R2 (DR5), which has a death domain in the cytoplasmic region. Two additional receptors, TRAIL-R3 (DCR1) with a glycophospholipid (GPI) anchor and TRAIL-R4 (DcR2) with a truncated death domain, do not signal apoptosis and can act as decoys. OPG may also act as a soluble decoy. TRAF binding motifs in the cytoplasmic regions of DR5 and DcR2 may be responsible for $\mathrm{NF}-\kappa \mathrm{B}$ activation by these receptors. 
The human and murine TRAIL proteins share $65 \%$ sequence identity. In contrast, human and cynomolgus monkey TRAIL are $98 \%$ homologous, and the receptor ectodomain sequence identity is $91 \%$ for DR4, $88 \%$ for DR5, 84\% for DcR2, and 99\% for OPG, whereas cynomolgus DcR1 appears to be a pseudogene. Indeed, human TRAIL binds with similar affinity to human and cynomolgus death receptors $(\mathrm{Kd}=0.5 \pm 0.2 \mathrm{nM})$ (Truneh, Sharma et al., 2000). The chimpanzee has homologs of DR4, DR5, DcR1, DcR2 and OPG, with sequence identities ranging from $97 \%$ to $99 \%$ of the human counterparts. Additionally, human TRAIL is capable of inducing apoptosis in the rhesus mammary tumor cell line CMMT110 and the transformed baboon lymphoblastoid cell line CB1, further supporting its cross-reactivity with non human primate death receptors. Thus, monkeys provide a more optimal model than rodents for preclinical safety assessment of human TRAIL.

\section{The signaling pathway of TRAIL-induced apoptosis}

Similar to Fas-L, TRAIL rapidly triggers apoptosis in many tumor cells ${ }^{25)}$. The interaction of TRAIL with its death receptors DR4 and DR5 is the initial step in TRAIL-induced apoptosis. The binding of TRAIL leads to trimerization of the death receptors and activation of receptor-mediated death pathway (Fig. 2). The activated death receptors recruit and activate an adaptor protein called Fas-associated death domain (FADD) through interactions between the death domain (DD) on the death receptors and FADD. The death effector domain (DED) of FADD recruits and activates caspase-8, leading to the formation of the death-inducing signaling complex $(\mathrm{DISC})^{26)}$. Like FasL, the response to TRAIL is cell type specific and might be characterized by two distinct cell death pathways: in type I cells, extrinsic signals lead to the activation of large amounts of caspase- 8 and the rapid cleavage of caspase- 3 prior to loss of mitochondria trans-membrane potential $\left({ }^{\triangle} \Psi \mathrm{m}\right)$. In contrast, in type II cells, amplification through the mitochondrial pathway (intrinsic pathway), initiated by cleavage of Bid by caspase-8, is required for cellular apoptosis. In this pathway, the truncated Bid (tBid) induces Bax and Bak mediated release of cytochrome $c$ and Smac/DIABLO from mitochondria. The released cytochrome $c$ binds to Apaf-1

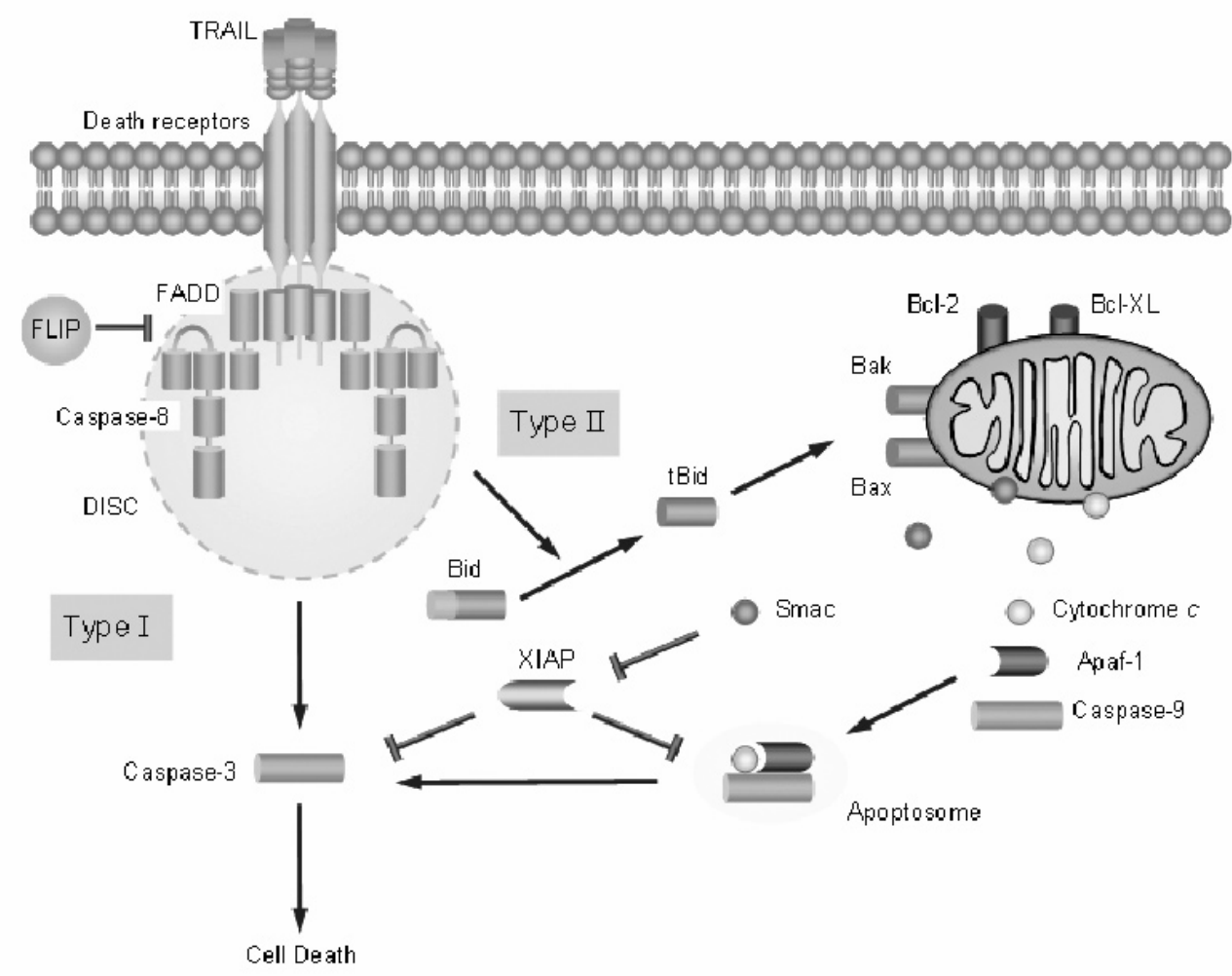

Fig. 2 TRAIL induced apoptosis signaling pathways. Trimerization of DR4 or DR5 by a TRAIL trimer leads to recruitment of an adaptor FADD, which in turn recruits and activates caspase-8. In certain cell types (type I), activation of caspase-8 is sufficient for activation of caspase-3, which executes cellular apoptosis (extrinsic pathway). In other cell types (type II), amplification through the mitochondrial pathway, which is initiated by cleavage of Bid by caspase- 8 and translocation of the truncated $\mathrm{Bid}(\mathrm{tBid})$ to mitochondria, leading to Bax/Bak-mediated release of cytochrome-c and thereby caspase- 9 activation by Apaf-1, is required for the caspase-3-mediated cellular apoptosis (intrinsic pathway). FLIP can prevent the recruitment of caspase-8. Bcl-2 and Bcl-xL can suppress the Bax/Bak mediated release of cytochrome $\mathrm{c}$ and $\mathrm{Smac} /$ DAIBLO from mitochondria. IAPs can attenuate the activities of caspase- 9 and caspase-3, although Smac/DIABLO can counteract IAPs. 


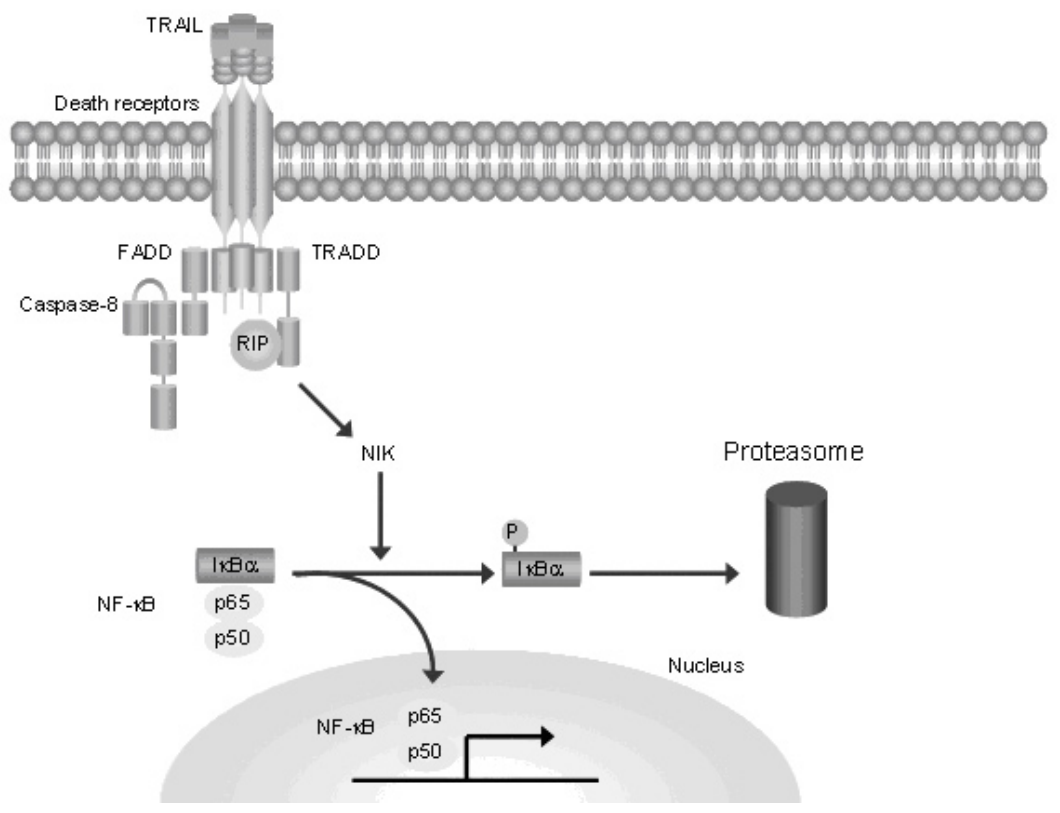

Fig. 3 TRAIL mediated NF- $\kappa B$ signaling through TRADD and RIP. Signaling of DR4 and DR5 results in the recruitment of RIP to an FADD. RIP can then activate NIK, which phosphorylates IKK leading to proteasome degradation of phosphorylated $\mathrm{lkB}$ as well as nuclear translocation and anti-apoptosis signaling of $\mathrm{NF}-\mathrm{kB}$.

activating caspase-9, which in turn activates the effector caspase-3. TRAIL appears to signal by a type II pathway in most tumor cells. Pro-apoptotic family members of the Bcl-2 family, such as Bax or its homologue Bak, are counteracted by the anti-apoptotic family members Bcl-2 or Bcl-xL. Other proteins belonging to the Bcl-2 family, such as Bim, Bid, PUMA, and NOXA, contain only one of the four Bcl-2 homology domains (BH3) common to the rest of the family and increase the activity of Bcl-2 family pro-apoptotic members. These proteins are referred to as BH3 domain only proteins. Smac/DIABLO binds to inhibitor of apoptosis proteins (IAPs), such as $\mathrm{X}$-chromosome-linked IAP (XIAP), preventing the IAPs from physically binding caspase-3, hence promoting further caspase- 3 activation.

Upon binding of TRAIL-R1, -R2, TRAIL can also activate the transcriptional factor $\mathrm{NF}-\kappa \mathrm{B}$ and $\mathrm{c}$-Jun $\mathrm{N}$-terminal kinase (JNK). The activation of NF- $\kappa \mathrm{B}$ or JNK by TRAIL is mediated via TRADD (TNFRassociated protein with death domain), and RIP (receptor-interacting protein) and occurs independently of caspase-8/-10 activation (Fig. 3 ).

\section{Modulation of sensitivity to TRAIL}

TRAIL induces apoptosis in many tumor cell lines, but is non-toxic to normal cells. The mechanisms underlying preferential killing of tumor cells over normal cells by TRAIL are not fully clear. Signal transduction to cell death can principally be blocked by an increase in the amount of antiapoptotic molecules involved in the regulation of apoptosis or by down-regulation of proapoptotic molecules. Sensitivity to anticancer therapy can be regulated at various levels along the signaling pathways. Importantly, cancer cells have evolved numerous ways to evade induction of apoptosis triggered by the death ligand TRAIL resulting in TRAIL resistance as outlined below.

\section{TRAIL receptors}

Loss of expression of the agonistic TRAIL receptors DR4 and DR5 can account for TRAIL resistance. Both receptors are located on chromosome 8p, a region of frequent loss of heterozygosity $(\mathrm{LOH})$ in tumors ${ }^{12)}$. In a small percentage of cancers, such as non-Hodgkin' s lymphoma, colorectal, breast, head and neck or lung carcinoma, deletions or mutations were found, which resulted in loss of both copies of DR4 or DR ${ }^{27-31)}$. In addition, loss of DR4 or DR5 expression may be caused by epigenetic alterations such as promoter hypermethylation in neuroblastoma ${ }^{32)}$. Consistent with these reports, it has recently been shown that loss of function of DR5 using a siRNA approach promotes colon tumor growth in xenografts and confers resistance to chemotherapy-induced apoptosis, suggesting DR5 may be a pivotal determinant for tumorigenesis and chemosensitivity ${ }^{33)}$.

Increased TRAIL sensitivity of tumor cells was initially postulated to result from the lack of DcR expression. TRAIL binds with high affinity to two receptors, DcR1 and DcR2, both incapable of transmitting an apoptotic signal due to absent or incomplete death domains. Overexpression of these receptors protects cells from apoptosis induction by TRAIL, suggesting that they act as "decoys", by sequestering the ligand from the signaling death receptors. Decoy receptor mRNAs are expressed in various normal tissues, and there is evidence 
supporting a protective role for these receptors in certain non-neoplastic cells. However, in most cancer cell lines, DR4 and/or DR5 are expressed, whereas DcR expression is less frequent and does not appear to correlate with resistance to TRAIL. Thus, there are probably additional determinants for TRAIL sensitivity besides the relationship between decoy and functional receptor expression.

\section{Caspases}

Given the important role of caspases as effector molecules in apoptosis, inhibition of caspase activation may be important in determiniing TRAIL resistance. Convincing evidence is accumulating, which shows caspase- 8 to be a key and irreplaceable molecule in TRAILinduced as well as Fas L- and TNF- $\alpha$-induced apoptosis. Caspase- 8 expression was found to be inactivated by hypermethylation of regulatory sequences of the caspase- 8 gene in a number of different neuroblastoma, and small lung cell carcinoma cells and tissue samples ${ }^{34-36)}$. These observations suggest that down regulation or loss of caspase- 8 expression can lead to TRAIL resistance. Importantly, restoration of caspase- 8 expression by gene transfer or by demethylation strategies sensitized resistant tumor cells to death receptor-mediated apoptosis.

\section{CFLIP}

TRAIL signaling can also be negatively influenced by intracellular proteins that associate with the cytoplasmitic domain of TRAIL receptors such as c-FLIP ${ }^{37)}$. c-FLIP has homology to caspase- 8 and -10 , but lacks protease activity $^{38)}$. It is therefore thought that FLIP recruitment to the DISC in place of the initiator caspases blocks their activation. c-FLIP exists as a long $\left(\mathrm{c}-\mathrm{FLIP}_{\mathrm{L}}\right)$ and a short isoform (c-FLIP $\left.{ }_{S}\right)$, both of which can inhibit death receptor-induced apoptosis. Interestingly, c-FLIP was identified in a screen for genes that could confer resistance to TRAIL-induced apoptosis ${ }^{39}$. High c-FLIP expression has been detected in many tumors and has been correlated with resistance to TRAIL-induced apoptosis. Overexpression studies suggest that FLIP is an inhibitor of caspase- 8 activation at the TRAIL DISC ${ }^{40,41)}$, and others have found correlations between FLIP levels and TRAIL resistance ${ }^{42)}$. Thus, FLIP appears to play an important role in TRAIL resistance.

\section{Inhibitor of apoptosis proteins}

Increased IAPs expression is detected in many tumors and has been correlated with adverse prognosis ${ }^{43)}$. IAP proteins can block apoptotic events by inhibiting the catalytic activity of effector caspases (caspase-3 and-7) or by blocking the activation of the apopsomal caspase- 9 by directly interacting with the active sites of these caspases. Each IAP contains one or three tandem repeats of evolutionarily conserved domains termed baculovirus inhibitory repeats (BIR). Different BIRs are thought to have different preferences for distinct caspases. So far, six mammalian IAPs have been identified: cIAP1, cIAP2, X-linked inhibitor of apoptosis (XIAP), neuronal apoptosis inhibitory protein (NAIP), survivin, and BIR repeat containing ubiquitin-conjugating enzyme (BRUCE). XIAP is the most potent inhibitor of caspase activity. High expression of IAPs in cancer cells can confer resistance to TRAIL-induced apoptosis. In addition to regulation of apoptosis, IAP members such as survivin are involved in the regulation of mitosis ${ }^{44)}$.

The activity of IAPs are controlled at various levels; The transcription factor $\mathrm{NF}-\kappa \mathrm{B}$ that has been reported to stimulate expression of cIAP1, cIAP2, and XIAP ${ }^{45}$. In addition, IAPs can be blocked by Smac/DIABLO, a mitochondrial protein that is released into the cytosol during the apoptotic cascade, where it promotes cell death by eliminating IAP inhibition of caspases ${ }^{46}$. Smac/Diablo is thought to interact with the BIR regions on IAPs, thereby, releasing the caspases and promoting apoptosis. Blocking the release of Smac/Diablo from the mitochondria has been associated with resistance to TRAIL in some, but not all, melanoma cell lines.

\section{Bcl-2 family}

Bcl-2 family proteins play an important role in the regulation of the mitochondrial pathway, because these proteins localize to intracellular membranes such as the mitochondrial membrane ${ }^{47)}$. They comprise both antiapoptotic members, $\mathrm{Bcl}-2$ or $\mathrm{Bcl}-\mathrm{X}_{\mathrm{L}}$, as well as proapoptotic molecules such as Bax or Bid. Altered expression of Bcl-2 family proteins have been reported in various human cancers. Imbalances in the ratio of anti- and proapoptotic Bcl-2 proteins may favor tumor cell survival instead of cell death. Overexpression of Bcl-2 or Bcl- $\mathrm{X}_{\mathrm{L}}$ blocked TRAIL-triggered apoptosis in many tumor cell lines, e.g., prostate carcinoma, pancreatic carcinoma, or glioblastoma cells ${ }^{48-50)}$. In addition, gene ablation studies showed that Bax was absolutely required for TRAILinduced apoptosis in colon carcinoma cells ${ }^{51)}$. However, overexpression of $\mathrm{Bcl}-2$ or $\mathrm{Bcl}-\mathrm{X}_{\mathrm{L}}$ did not interfere with TRAIL-induced apoptosis in some cell types such as Jurkat or CEM T cell leukemia cells ${ }^{52)}$. Thus, the contribution of the mitochondrial pathway to TRAIL-induced apoptosis may depend on the cell type.

Recently, we have shown that Mcl-1, an anti-apoptotic Bcl-2 protein, appears to regulate the sensitivity to TRAIL $^{53)}$. We used RNA interference (RNAi) to specifically reduce Mcl-1 expression in a human cholangiocarcinoma cell line that is resistant to TRAIL. Mcl-1 depletion sensitized cells to TRAIL-mediated apoptosis. Our data demonstrates that Mcl-1 mediates TRAIL resistance in cholangiocarcinoma cells by blocking the mitochondrial pathway of cell death. 


\section{NF- $\kappa$ B}

$\mathrm{NF}-\kappa \mathrm{B}$ is potently and rapidly activated after TNF binding to TNFR1, generating a prosurvival signal that must be overcome in many cell lines to enable TNF to induce apoptosis. NF- $\kappa \mathrm{B}$ has been reported to induce expression of FLIP, Bcl- $\mathrm{X}_{\mathrm{L}}$, and XIAP, which are considered to be responsible for its ability to protect cells from death. While TRAIL can also activate NF- $\mathrm{\kappa B}^{18,54)}$, this stimulation is significantly attenuated and delayed as compared to that of TNF, and requires a high concentration of the ligand. Thus, NF- $\mathrm{KB}$ induction by TRAIL may be a secondary, indirect event. Nonetheless, in a cancer cell line with high constitutive NF- $\mathrm{KB}$ activity, specific downregulation of NF- $\mathrm{KB}$ by inactivation of the I- $\kappa \mathrm{B}$ kinase significantly sensitized the cells to TRAIL ${ }^{55}$. Thus while TRAIL is unlikely to activate NF$\kappa \mathrm{B}$ directly, in some contexts this transcription factor can moderate sensitivity to the ligand.

\section{Akt}

There are numerous reports that activation of the phosphatidylinositol 3-kinase/Akt pathway inhibits TRAIL-induced apoptosis in a wide variety of tumor cells ${ }^{56-58)}$. The mechanism by which activation of Akt suppresses apoptosis may differ between cell types. Akt has been shown to induce the expression of c-FLIP, which can block TRAIL-induced apoptosis ${ }^{59)}$. Akt can also induce NF- $\mathrm{KB}$ activation, which can then suppress apoptosis as indicated previously. More recently, we have demonstrated that Akt regulates the antiapoptotic Bcl-2 protein, Mcl-1 by post-translational processes in cholangiocarcinoma cell lines, which leads to resistant to TRAIL-mediated apoptosis ${ }^{60)}$. What may induce Akt activation leading to suppression of apoptosis induced by TRAIL may also vary. For instance some cells constitutively express active Akt such as in prostate cancer cells ${ }^{61}$. Epidermal growth factor receptor (EGFR) signaling can also activate Akt, inducing resistance to TRAIL ${ }^{62}$. In our study, the inflammatory cytokine IL-6 upregulates Akt, inducing Mcl-1, which blocks apoptosis. Interestingly, however, in some cells such as Jurkat T cells, TRAIL itself can activate Akt, leading to apoptosis resistance ${ }^{63)}$. In human colon cancer cells, it was shown that the expression of TRAIL itself is regulated by activation of $\mathrm{Akt}^{64)}$, suggesting an autocrine loop. Thus all these reports indicate that Akt plays an important role in TRAIL-induced apoptosis.

In summary, a balance between pro- and anti-apoptotic factors that exist at the cell-surface and within the cell determines susceptibility to TRAIL-induced cell death. A better understanding of this relationship will facilitate identification of patients whose tumors might be most sensitive to TRAIL therapy. Moreover, defining the mechanisms that permit tumor cells to acquire resistance to TRAIL will be helpful in developing strategies that maximize the potential effectiveness of this agent in clinical application.

\section{Physiological roles of TRAIL}

Since it was discovered in $1995^{10)}$, the direct cytotoxic effect of soluble recombinant TRAIL on a variety of tumor cells has been widely studied. In numerous in vitro studies, certain tumor cells have been shown to be sensitive to TRAIL-induced apoptosis ${ }^{11,65)}$. However, it did not induce apoptosis in most normal cells, including renal proximal tubule epithelial cells, lung fibroblasts, mammary epithelial cells, skeletal muscle cells, astrocytes, melanocytes, colon smooth muscle cells, or hepatocytes $^{66,67)}$. Several studies have also shown that although non-transformed cells such as keratinocytes ${ }^{68)}$ and $\mathrm{PBL}^{69)}$ express TRAIL and TRAIL receptors, they are not sensitive to the cytotoxic effects of TRAIL.

In addition to its proapoptotic activity, several studies point to a role for TRAIL in immune functions. It has been shown that TRAIL-deficient mice have a severe defect in thymocyte apoptosis and are also hypersensitive to autoimmune diseases ${ }^{70)}$. Consistent with this report, TRAIL appears to inhibit autoimmune inflammation in experimentally induced rheumatoid arthritis ${ }^{71)}$ and multiple sclerosis ${ }^{72}$. Dendritic cells are the most potent antigen presenting cells for initiation of immune responses including antitumor immune responses. Human immature dendritic cells have been shown to express TNF, FasL, and TRAIL on their cell surface ${ }^{73)}$ and be capable of inducing cancer cell apoptosis through these death ligands. Other authors have demonstrated that human dendritic cells express TRAIL on their surface after stimulation with IFN- $\alpha$ or IFN- $\gamma$ and acquire the ability to kill TRAIL sensitive tumor cells ${ }^{13}$. Similar effects are seen when monocytes are treated with IFN- $\alpha$ or IFN- $\gamma$. TRAIL is upregulated and monocyte antitumor cytotoxicity seems to be dependent on TRAIL induced apoptosis $^{14)}$. TRAIL is also induced on the surface of human peripheral blood $\mathrm{T}$ cells upon stimulation of TCR receptor or treatment with type I IFNs. The cytotoxic activity of these T cells was demonstrated to be TRAIL dependent ${ }^{74)}$. TRAIL is also expressed in mouse liver NK cells but not on other lymphocytes isolated from liver or spleen. By administration of neutralizing monoclonal antibody against TRAIL to mice subcutaneously inoculated with TRAIL-sensitive tumors, it was demonstrated that blocking endogeneous TRAIL activity promoted outgrowth of these tumors ${ }^{75}$. TRAIL also makes a critical contribution to the NK cell-mediated suppression of liver metastasis ${ }^{76)}$. TRAIL expression in NK cells and the antitumor and antimetastatic potential of these cells were dependent on the presence of IFN- $\gamma$. Thus, TRAIL, as a physiologic mediator, is a tumor suppressor.

Little is known of TRAIL's physiological role in 
TRAIL-resistant tumor cells, however, recent studies have shown that FasL promotes tumor progression by facilitating cell invasion and migration ${ }^{77,78)}$. Likewise, it has been shown that TRAIL induces a proangiogenic phenotype in human endothelial cells, including an increase in both migration and invasion ${ }^{79)}$. Indeed, TRAIL was highly expressed in poorly differentiated non-small cell lung cancer tumor ${ }^{80)}$, and pancreas cancer ${ }^{81)}$, which are resistant to chemotherapy and radiation. Similarly, TRAIL is expressed by a subset of lymphomas ${ }^{82)}$, malignant plasmocytoma cells ${ }^{83)}$, and ovarian carcinomas ${ }^{84)}$, in which TRAIL expression has been correlated with the degree of malignancy. Interestingly, increased expression of TRAIL was observed by PCR and/or flow cytometry after IFN- $\gamma$ stimulation in colon cancer cell ${ }^{85}$, and hepatoma cells ${ }^{86)}$. Consistent with these reports, we have found that TRAIL is not only paradoxically expressed in human cholangiocarcinoma, but also promotes cell migration (Ishimura, unpublished data). Thus, TRAIL is able to promote survival or proliferation as well as migration in TRAIL-resistant tumor cells.

\section{Therapeutic attempts to target the cell death machinery}

Death receptors can trigger apoptosis independently of $\mathrm{p} 53$, which is inactivated in more than half of human cancers ${ }^{87)}$. Therefore, death receptor ligands are likely effective against tumors that have acquired resistance to chemotherapy or radiotherapy. In addition, they may be useful in combination with conventional therapies against tumors that retain at least partial sensitivity to chemotherapy or radiation.

Despite these potential advantages, clinical application of the prototypic death receptor ligands TNF and Fas has been hampered by toxicity to normal tissues ${ }^{88)}$. Systemic administration of Fas-L causes a severe inflammatory response syndrome or massive liver cell apoptosis, and relatively low concentrations of TNF- $\alpha$ given intravenously cause hypotention and a systemic inflammatory response syndrome that resembles septic shock by activating the pro-inflammatory $\mathrm{NF}-\kappa \mathrm{B}$ in vascular endothelial cells and macrophages. To circumvent the toxicity, perfusion of extremities with high concentration of TNF- $\alpha$ has been used to enhance local and regional control of large soft tissue sarcoma and in-transit metastases for melanoma ${ }^{89-91)}$. In these investigations, TNF- $\alpha$ is administered intra-arterially and sometimes combined with melphalan, interferon- $\gamma$, or heperthermia. The demonstration that limb perfusion is associated with significant antitumor activity has supported a role for TNF- $\alpha$ as a local and regional antitumor agent. The strategy of regional perfusion with TNF- $\alpha$ has also been extended to patients with liver metastases ${ }^{92)}$. In contrast, TRAIL appears to be a relatively safe and promising candidate for clinical application, particularly in its non-tagged, zinc-bound homotrimeric form ${ }^{12)}$. Indeed, the ability of TRAIL to induce apoptosis in a wide variety of cancer cell lines, while having little toxicity toward many types of normal cells. In mouse models, TRAIL demonstrated remarkable efficacy against tumor xenografts of colon carcinoma $^{93)}$, breast carcinoma ${ }^{66)}$, multiple myeloma ${ }^{94)}$, and glioma ${ }^{95)}$. Currently, an agonistic human monoclonal antibody to TRAIL-R1 is in phase II trials for the treatment of human cancers.

The scenario emerging from all these studies is that the therapeutic use of death ligand as an inducer of tumor specific cell death may be considered as a useful strategy to overcome resistance of cancer cells to conventional chemotherapeutic agents ${ }^{96)}$. However some concerns are inevitable in light of a very recent report showing that not only Fas-L but also TRAIL are able to induce cancer cell migration in a wide range of neoplastic diseases ${ }^{77,79,97)}$. Given the promising therapeutic potential of TRAIL as a novel anticancer drug, TRAIL-mediated survival or proliferation of target cells may restrict its use to apoptosissensitive tumors and may represent a potential risk for patients with TRAIL apoptosis resistant tumor cells as it might increase tumor growth. Further studies based on in vivo animal models of TRAIL apoptosis resistant tumors are necessary to elaborate the clinical relevance of TRAIL mediated survival and proliferation of TRAIL apoptosis resistant tumors.

\section{Conclusions}

TRAIL is a potent inducer of apoptosis in most tumor cells. IFNs are important modulators of TRAIL expression, and consistent with this finding, the ligand seems to play an important role in surveillance by cells of the innate immune system against malignant transformation and viral-infection of host cells. Because of the differential toxicity towards transformed versus normal cells, TRAIL shows promise as a potential cancer therapeutic agent, and work is underway to enable its investigation in cancer patients. TRAIL-R2 agonistic monoclonal antibody therapy is currently being tested in phase II clinical trials. However, the physiological role for TRAIL in TRAIL-resistant cells remains to be characterized. Further basic studies to elucidate the mechanisms of the TRAIL resistance of normal cells, as well as tumor cells, are still needed to improve the anti-tumor effect of this strategy and the clinical relevance of TRAIL-mediated survival and proliferation of TRAIL resistant tumors.

\section{References}

1) Hengartner, M. O. (2000). The biochemistry of apoptosis. Nature. 407: 770-776

2) Krammer, P. H. (1999). CD95(APO-1/Fas)-mediated apoptosis: live and let die. Adv. Immunol. 71: 163-210.

3) Schmitz, I., Kirchhoff, S. and Krammer, P. H. (2000). Regulation 
of death receptor-mediated apoptosis pathways. Int. J. Biochem. Cell Biol. 32: 1123-1136.

4) Thornberry, N. A. and Lazebnik, Y. (1998). Caspases: enemies within. Science. 281: 1312-1316.

5) Igney, F. H. and Krammer, P. H. (2002). Immune escape of tumors: apoptosis resistance and tumor counterattack. J. Leukoc. Biol. 71: 907-920.

6) Ashkenazi, A. (2002). Targeting death and decoy receptors of the tumour-necrosis factor superfamily. Nat. Rev. Cancer. 2: 420-430.

7) Bodmer, J. L., Schneider, P. and Tschopp, J. (2002). The molecular architecture of the TNF superfamily. Trends Biochem. Sci. 27: 19-26.

8) Ashkenazi, A. and Dixit, V. M. (1998). Death receptors: signaling and modulation. Science. 281: 1305-1308.

9) Locksley, R. M., Killeen, N. and Lenardo, M. J. (2001). The TNF and TNF receptor superfamilies: integrating mammalian biology. Cell. 104: 487-501.

10) Wiley, S. R., Schooley, K., Smolak, P. J., Din, W. S., Huang, C. P., Nicholl, J. K., Sutherland, G. R., Smith, T. D., Rauch, C., Smith, C. A. and et al. (1995). Identification and characterization of a new member of the TNF family that induces apoptosis. Immunity. 3 : 673-682.

11) Pitti, R. M., Marsters, S. A., Ruppert, S., Donahue, C. J., Moore, A. and Ashkenazi, A. (1996). Induction of apoptosis by Apo-2 ligand, a new member of the tumor necrosis factor cytokine family. J. Biol. Chem. 271: 12687-12690.

12) LeBlanc, H. N. and Ashkenazi, A. (2003). Apo2L/TRAIL and its death and decoy receptors. Cell Death Differ. 10: 66-75.

13) Fanger, N. A., Maliszewski, C. R., Schooley, K. and Griffith, T. S. (1999). Human dendritic cells mediate cellular apoptosis via tumor necrosis factor-related apoptosis-inducing ligand (TRAIL). J. Exp. Med. 190: 1155-1164.

14) Griffith, T. S., Wiley, S. R., Kubin, M. Z., Sedger, L. M., Maliszewski, C. R. and Fanger, N. A. (1999). Monocyte-mediated tumoricidal activity via the tumor necrosis factor-related cytokine, TRAIL. J. Exp. Med. 189: 1343-1354.

15) Johnsen, A. C., Haux, J., Steinkjer, B., Nonstad, U., Egeberg, K., Sundan, A., Ashkenazi, A. and Espevik, T. (1999). Regulation of APO-2 ligand/trail expression in NK cells-involvement in NK cellmediated cytotoxicity. Cytokine. 11: 664-672.

16) Hymowitz, S. G., Christinger, H. W., Fuh, G., Ultsch, M., O'Connell, M., Kelley, R. F., Ashkenazi, A. and de Vos, A. M. (1999). Triggering cell death: the crystal structure of Apo2L/ TRAIL in a complex with death receptor 5. Mol. Cell. 4: 563-571.

17) Pan, G., O'Rourke, K., Chinnaiyan, A. M., Gentz, R., Ebner, R., $\mathrm{Ni}$ J. and Dixit, V. M. (1997). The receptor for the cytotoxic ligand TRAIL. Science. 276: 111-113.

18) Chaudhary, P. M., Eby, M., Jasmin, A., Bookwalter, A., Murray, J. and Hood, L. (1997). Death receptor 5, a new member of the TNFR family, and DR4 induce FADD-dependent apoptosis and activate the NF-kappaB pathway. Immunity. 7: 821-830.

19) Pan, G., Ni, J., Wei, Y. F., Yu, G., Gentz, R. and Dixit, V. M. (1997). An antagonist decoy receptor and a death domain-containing receptor for TRAIL. Science. 277: 815-818.

20) Degli-Esposti, M. A., Smolak, P. J., Walczak, H., Waugh, J., Huang, C. P., DuBose, R. F., Goodwin, R. G. and Smith, C. A. (1997). Cloning and characterization of TRAIL-R3, a novel member of the emerging TRAIL receptor family. J. Exp. Med. 186: 1165-1170.

21) Degli-Esposti, M. A., Dougall, W. C., Smolak, P. J., Waugh, J. Y., Smith, C. A. and Goodwin, R. G. (1997). The novel receptor TRAIL-R4 induces NF-kappaB and protects against TRAILmediated apoptosis, yet retains an incomplete death domain. Immunity. 7: 813-820.

22) Marsters, S. A., Sheridan, J. P., Pitti, R. M., Huang, A., Skubatch, M., Baldwin, D., Yuan, J., Gurney, A., Goddard, A. D., Godowski, P. and Ashkenazi, A. (1997). A novel receptor for Apo2L/TRAIL contains a truncated death domain. Curr. Biol. 7: 1003-1006.

23) Simonet, W. S., Lacey, D. L., Dunstan, C. R., Kelley, M., Chang, M. S., Luthy, R., Nguyen, H. Q., Wooden, S., Bennett, L., Boone, T., Shimamoto, G., DeRose, M., Elliott, R., Colombero, A., Tan, H.
L., Trail, G., Sullivan, J., Davy, E., Bucay, N., Renshaw-Gegg, L., Hughes, T. M., Hill, D., Pattison, W., Campbell, P., Boyle, W. J. and et al. (1997). Osteoprotegerin: a novel secreted protein involved in the regulation of bone density. Cell. 89: 309-319.

24) Emery, J. G., McDonnell, P., Burke, M. B., Deen, K. C., Lyn, S., Silverman, C., Dul, E., Appelbaum, E. R., Eichman, C., DiPrinzio, R., Dodds, R. A., James, I. E., Rosenberg, M., Lee, J. C. and Young, P. R. (1998). Osteoprotegerin is a receptor for the cytotoxic ligand TRAIL. J. Biol. Chem. 273: 14363-14367.

25) Wajant, H., Pfizenmaier, K. and Scheurich, P. (2002). TNF-related apoptosis inducing ligand (TRAIL) and its receptors in tumor surveillance and cancer therapy. Apoptosis. 7: 449-459.

26) Kischkel, F. C., Hellbardt, S., Behrmann, I., Germer, M., Pawlita, M., Krammer, P. H. and Peter, M. E. (1995). Cytotoxicitydependent APO-1 (Fas/CD95)-associated proteins form a deathinducing signaling complex (DISC) with the receptor. Embo J. 14: 5579-5588.

27) Arai, T., Akiyama, Y., Okabe, S., Saito, K., Iwai, T. and Yuasa, Y. (1998). Genomic organization and mutation analyses of the DR5/ TRAIL receptor 2 gene in colorectal carcinomas. Cancer Lett. 133: 197-204.

28) Pai, S. I., Wu, G. S., Ozoren, N., Wu, L., Jen, J., Sidransky, D. and El-Deiry, W. S. (1998). Rare loss-of-function mutation of a death receptor gene in head and neck cancer. Cancer Res. 58: 3513-3518.

29) Lee, S. H., Shin, M. S., Kim, H. S., Lee, H. K., Park, W. S., Kim, S. Y., Lee, J. H., Han, S. Y., Park, J. Y., Oh, R. R., Jang, J. J., Han, J. Y., Lee, J. Y. and Yoo, N. J. (1999). Alterations of the DR5/TRAIL receptor 2 gene in non-small cell lung cancers. Cancer Res. 59: 5683-5686.

30) Lee, S. H., Shin, M. S., Kim, H. S., Lee, H. K., Park, W. S., Kim, S. Y., Lee, J. H., Han, S. Y., Park, J. Y., Oh, R. R., Kang, C. S., Kim, K. M., Jang, J. J., Nam, S. W., Lee, J. Y. and Yoo, N. J. (2001). Somatic mutations of TRAIL-receptor 1 and TRAIL-receptor 2 genes in non-Hodgkin's lymphoma. Oncogene. 20: 399-403.

31) Shin, M. S., Kim, H. S., Lee, S. H., Park, W. S., Kim, S. Y., Park, J. Y., Lee, J. H., Lee, S. K., Lee, S. N., Jung, S. S., Han, J. Y., Kim, H., Lee, J. Y. and Yoo, N. J. (2001). Mutations of tumor necrosis factor-related apoptosis-inducing ligand receptor 1 (TRAIL-R1) and receptor 2 (TRAIL-R2) genes in metastatic breast cancers. Cancer Res. 61: 4942-4946.

32) van Noesel, M. M., van Bezouw, S., Salomons, G. S., Voute, P. A., Pieters, R., Baylin, S. B., Herman, J. G. and Versteeg, R. (2002). Tumor-specific down-regulation of the tumor necrosis factorrelated apoptosis-inducing ligand decoy receptors DcR1 and DcR2 is associated with dense promoter hypermethylation. Cancer Res. 62: 2157-2161.

33) Wang, S. and El-Deiry, W. S. (2004). Inducible silencing of KILLER/DR5 in vivo promotes bioluminescent colon tumor xenograft growth and confers resistance to chemotherapeutic agent 5-fluorouracil. Cancer Res. 64: 6666-6672.

34) Teitz, T., Wei, T., Valentine, M. B., Vanin, E. F., Grenet, J., Valentine, V. A., Behm, F. G., Look, A. T., Lahti, J. M. and Kidd, V. J. (2000). Caspase 8 is deleted or silenced preferentially in childhood neuroblastomas with amplification of MYCN. Nat. Med. 6: 529-535.

35) Fulda, S., Kufer, M. U., Meyer, E., van Valen, F., DockhornDworniczak, B. and Debatin, K. M. (2001). Sensitization for death receptor- or drug-induced apoptosis by re-expression of caspase- 8 through demethylation or gene transfer. Oncogene. 20: 5865-5877.

36) Baylin, S. and Bestor, T. H. (2002). Altered methylation patterns in cancer cell genomes: cause or consequence? Cancer Cell. 1: 299-305.

37) Krueger, A., Baumann, S., Krammer, P. H. and Kirchhoff, S. (2001). FLICE-inhibitory proteins: regulators of death receptor-mediated apoptosis. Mol. Cell. Biol. 21: 8247-8254.

38) Tschopp, J., Irmler, M. and Thome, M. (1998). Inhibition of fas death signals by FLIPs. Curr. Opin. Immunol. 10: 552-558.

39) Burns, T. F. and El-Deiry, W. S. (2001). Identification of inhibitors of TRAIL-induced death (ITIDs) in the TRAIL-sensitive colon carcinoma cell line SW480 using a genetic approach. J. Biol. 
Chem. 276: 37879-37886.

40) Irmler, M., Thome, M., Hahne, M., Schneider, P., Hofmann, K., Steiner, V., Bodmer, J. L., Schroter, M., Burns, K., Mattmann, C., Rimoldi, D., French, L. E. and Tschopp, J. (1997). Inhibition of death receptor signals by cellular FLIP. Nature. 388: 190-195.

41) Wang, J., Lobito, A. A., Shen, F., Hornung, F., Winoto, A. and Lenardo, M. J. (2000). Inhibition of Fas-mediated apoptosis by the B cell antigen receptor through c-FLIP. Eur. J. Immunol. 30: 155-163.

42) Griffith, T. S., Chin, W. A., Jackson, G. C., Lynch, D. H. and Kubin, M. Z. (1998). Intracellular regulation of TRAIL-induced apoptosis in human melanoma cells. J. Immunol. 161: 2833-2840.

43) Hersey, P. and Zhang, X. D. (2001). How melanoma cells evade trail-induced apoptosis. Nat. Rev. Cancer. 1: 142-150.

44) Altieri, D. C. (2003). Validating survivin as a cancer therapeutic target. Nat. Rev. Cancer. 3: 46-54.

45) Salvesen, G. S. and Duckett, C. S. (2002). IAP proteins: blocking the road to death's door. Nat. Rev. Mol. Cell. Biol. 3: 401-410.

46) van Loo, G., Saelens, X., van Gurp, M., MacFarlane, M., Martin, S. J. and Vandenabeele, P. (2002). The role of mitochondrial factors in apoptosis: a Russian roulette with more than one bullet. Cell Death Differ. 9: 1031-1042.

47) Cory, S. and Adams, J. M. (2002). The Bcl2 family: regulators of the cellular life-or-death switch. Nat. Rev. Cancer. 2: 647-656.

48) Hinz, S., Trauzold, A., Boenicke, L., Sandberg, C., Beckmann, S., Bayer, E., Walczak, H., Kalthoff, H. and Ungefroren, H. (2000). Bcl-XL protects pancreatic adenocarcinoma cells against CD95- and TRAIL-receptor-mediated apoptosis. Oncogene. 19: 5477-5486.

49) Munshi, A., Pappas, G., Honda, T., McDonnell, T. J., Younes, A., Li, Y. and Meyn, R. E. (2001). TRAIL (APO-2L) induces apoptosis in human prostate cancer cells that is inhibitable by $\mathrm{Bcl}-2$. Oncogene. 20: 3757-3765.

50) Fulda, S. and Debatin, K. M. (2002). IFNgamma sensitizes for apoptosis by upregulating caspase- 8 expression through the Stat1 pathway. Oncogene. 21: 2295-2308.

51) Deng, Y., Lin, Y. and Wu, X. (2002). TRAIL-induced apoptosis requires Bax-dependent mitochondrial release of Smac/DIABLO. Genes Dev. 16: 33-45.

52) Walczak, H., Bouchon, A., Stahl, H. and Krammer, P. H. (2000). Tumor necrosis factor-related apoptosis-inducing ligand retains its apoptosis-inducing capacity on Bcl-2- or Bcl-xL-overexpressing chemotherapy-resistant tumor cells. Cancer Res. 60: 3051-3057.

53) Taniai, M., Grambihler, A., Higuchi, H., Werneburg, N., Bronk, S. F., Farrugia, D. J., Kaufmann, S. H. and Gores, G. J. (2004). Mcl-1 mediates tumor necrosis factor-related apoptosis-inducing ligand resistance in human cholangiocarcinoma cells. Cancer Res. 64: 3517-3524.

54) Schneider, P., Thome, M., Burns, K., Bodmer, J. L., Hofmann, K., Kataoka, T., Holler, N. and Tschopp, J. (1997). TRAIL receptors 1 (DR4) and 2 (DR5) signal FADD-dependent apoptosis and activate NF-kappaB. Immunity. 7: 831-836.

55) Luo, J. L., Maeda, S., Hsu, L. C., Yagita, H. and Karin, M. (2004). Inhibition of NF-kappaB in cancer cells converts inflammationinduced tumor growth mediated by TNFalpha to TRAIL-mediated tumor regression. Cancer Cell. 6: 297-305.

56) Park, S. Y. and Seol, D. W. (2002). Regulation of Akt by EGF-R inhibitors, a possible mechanism of EGF-R inhibitor-enhanced TRAIL-induced apoptosis. Biochem. Biophys. Res. Commun. 295: 515-518.

57) Asakuma, J., Sumitomo, M., Asano, T., Asano, T. and Hayakawa, M. (2003). Selective Akt inactivation and tumor necrosis actorrelated apoptosis-inducing ligand sensitization of renal cancer cells by low concentrations of paclitaxel. Cancer Res. 63: 1365-1370.

58) Milani, D., Zauli, G., Rimondi, E., Celeghini, C., Marmiroli, S., Narducci, P., Capitani, S. and Secchiero, P. (2003). Tumour necrosis factor-related apoptosis-inducing ligand sequentially activates pro-survival and pro-apoptotic pathways in SK-N-MC neuronal cells. J. Neurochem. 86: 126-135.

59) Nam, S. Y., Amoscato, A. A. and Lee, Y. J. (2002). Low glucose- enhanced TRAIL cytotoxicity is mediated through the ceramideAkt-FLIP pathway. Oncogene. 21: 337-346.

60) Kobayashi, S., Werneburg, N.W., Bronk, S.F., Kaufmann, S.H., and Gores, G.J. Interleukin-6 contributes to Mcl-1 upregulation and TRAIL resistance via an Akt signaling pathway in cholangiocarcinoma cells. Gastroenterology. in press.

61) Chen, X., Thakkar, H., Tyan, F., Gim, S., Robinson, H., Lee, C., Pandey, S. K., Nwokorie, C., Onwudiwe, N. and Srivastava, R. K. (2001). Constitutively active Akt is an important regulator of TRAIL sensitivity in prostate cancer. Oncogene. 20: 6073-6083.

62) Ivanov, V. N. and Hei, T. K. (2005). Combined treatment with EGFR inhibitors and arsenite upregulated apoptosis in human EGFR-positive melanomas: a role of suppression of the PI3K-AKT pathway. Oncogene. 24: 616-626.

63) Zauli, G., Sancilio, S., Cataldi, A., Sabatini, N., Bosco, D. and Di Pietro, R. (2005). PI-3K/Akt and NF-kappaB/IkappaBalpha pathways are activated in Jurkat $\mathrm{T}$ cells in response to TRAIL treatment. J. Cell Physiol. 202: 900-911.

64) Wang, Q., Wang, X., Hernandez, A., Hellmich, M. R., Gatalica, Z. and Evers, B. M. (2002). Regulation of TRAIL expression by the phosphatidylinositol 3-kinase/Akt/GSK-3 pathway in human colon cancer cells. J. Biol. Chem. 277: 36602-36610.

65) Zhang, X. D., Franco, A., Myers, K., Gray, C., Nguyen, T. and Hersey, P. (1999). Relation of TNF-related apoptosis-inducing ligand (TRAIL) receptor and FLICE-inhibitory protein expression to TRAIL-induced apoptosis of melanoma. Cancer Res. 59: 2747-2753.

66) Walczak, H., Miller, R. E., Ariail, K., Gliniak, B., Griffith, T. S., Kubin, M., Chin, W., Jones, J., Woodward, A., Le, T., Smith, C., Smolak, P., Goodwin, R. G., Rauch, C. T., Schuh, J. C. and Lynch, D. H. (1999). Tumoricidal activity of tumor necrosis factor-related apoptosis-inducing ligand in vivo. Nat. Med. 5: 157-163.

67) Lawrence, D., Shahrokh, Z., Marsters, S., Achilles, K., Shih, D., Mounho, B., Hillan, K., Totpal, K., DeForge, L., Schow, P., Hooley, J., Sherwood, S., Pai, R., Leung, S., Khan, L., Gliniak, B., Bussiere, J., Smith, C. A., Strom, S. S., Kelley, S., Fox, J. A., Thomas, D. and Ashkenazi, A. (2001). Differential hepatocyte toxicity of recombinant Apo2L/TRAIL versions. Nat. Med. 7: 383-385.

68) Kothny-Wilkes, G., Kulms, D., Poppelmann, B., Luger, T. A., Kubin, M. and Schwarz, T. (1998). Interleukin-1 protects transformed keratinocytes from tumor necrosis factor-related apoptosisinducing ligand. J Biol Chem. 273: 29247-29253.

69) Kayagaki, N., Yamaguchi, N., Nakayama, M., Eto, H., Okumura, K. and Yagita, H. (1999). Type I interferons (IFNs) regulate tumor necrosis factor-related apoptosis-inducing ligand (TRAIL) expression on human T cells: A novel mechanism for the antitumor effects of type I IFNs. J. Exp. Med. 189: 1451-1460.

70) Lamhamedi-Cherradi, S. E., Zheng, S. J., Maguschak, K. A., Peschon, J. and Chen, Y. H. (2003). Defective thymocyte apoptosis and accelerated autoimmune diseases in TRAIL-/- mice. Nat. Immunol. 4: 255-260.

71) Song, K., Chen, Y., Goke, R., Wilmen, A., Seidel, C., Goke, A., Hilliard, B. and Chen, Y. (2000). Tumor necrosis factor-related apoptosis-inducing ligand (TRAIL) is an inhibitor of autoimmune inflammation and cell cycle progression. J. Exp. Med. 191: 1095-1104.

72) Hilliard, B., Wilmen, A., Seidel, C., Liu, T. S., Goke, R. and Chen, Y. (2001). Roles of TNF-related apoptosis-inducing ligand in experimental autoimmune encephalomyelitis. J. Immunol. 166: 1314-1319.

73) Lu, G., Janjic, B. M., Janjic, J., Whiteside, T. L., Storkus, W. J. and Vujanovic, N. L. (2002). Innate direct anticancer effector function of human immature dendritic cells. II. Role of TNF, lymphotoxinalpha(1)beta(2), Fas ligand, and TNF-related apoptosis-inducing ligand. J. Immunol. 168: 1831-1839.

74) Kayagaki, N., Yamaguchi, N., Nakayama, M., Kawasaki, A., Akiba, H., Okumura, K. and Yagita, H. (1999). Involvement of TNF-related apoptosis-inducing ligand in human CD4+ T cellmediated cytotoxicity. J. Immunol. 162: 2639-2647.

75) Takeda, K., Smyth, M. J., Cretney, E., Hayakawa, Y., Yamaguchi, 
N., Yagita, H. and Okumura, K. (2001). Involvement of tumor necrosis factor-related apoptosis-inducing ligand in NK cell-mediated and IFN-gamma-dependent suppression of subcutaneous tumor growth. Cell Immunol. 214: 194-200.

76) Takeda, K., Hayakawa, Y., Smyth, M. J., Kayagaki, N., Yamaguchi, N., Kakuta, S., Iwakura, Y., Yagita, H. and Okumura, K. (2001). Involvement of tumor necrosis factor-related apoptosis-inducing ligand in surveillance of tumor metastasis by liver natural killer cells. Nat. Med. 7: 94-100

77) Barnhart, B. C., Legembre, P., Pietras, E., Bubici, C., Franzoso, G. and Peter, M. E. (2004). CD95 ligand induces motility and invasiveness of apoptosis-resistant tumor cells. Embo J. 23: 3175-3185.

78) Legembre, P., Schickel, R., Barnhart, B. C. and Peter, M. E. (2004). Identification of SNF1/AMP kinase-related kinase as an NFkappaB-regulated anti-apoptotic kinase involved in CD95-induced motility and invasiveness. J. Biol. Chem. 279: 46742-46747.

79) Secchiero, P., Gonelli, A., Carnevale, E., Corallini, F., Rizzardi, C., Zacchigna, S., Melato, M. and Zauli, G. (2004). Evidence for a proangiogenic activity of TNF-related apoptosis-inducing ligand. Neoplasia. 6: 364-373.

80) Spierings, D. C., de Vries, E. G., Timens, W., Groen, H. J., Boezen, H. M. and de Jong, S. (2003). Expression of TRAIL and TRAIL death receptors in stage III non-small cell lung cancer tumors. Clin. Cancer Res. 9: 3397-3405.

81) Ozawa, F., Friess, H., Kleeff, J., Xu, Z. W., Zimmermann, A., Sheikh, M. S. and Buchler, M. W. (2001). Effects and expression of TRAIL and its apoptosis-promoting receptors in human pancreatic cancer. Cancer Lett. 163: 71-81.

82) Zhao, S., Asgary, Z., Wang, Y., Goodwin, R., Andreeff, M. and Younes, A. (1999). Functional expression of TRAIL by lymphoid and myeloid tumour cells. Br. J. Haematol. 106: 827-832.

83) Silvestris, F., Cafforio, P., Tucci, M. and Dammacco, F. (2002). Negative regulation of erythroblast maturation by Fas-L $(+) /$ TRAIL(+) highly malignant plasma cells: a major pathogenetic mechanism of anemia in multiple myeloma. Blood. 99: 1305-1313.

84) Lancaster, J. M., Sayer, R., Blanchette, C., Calingaert, B., Whitaker, R., Schildkraut, J., Marks, J. and Berchuck, A. (2003). High expression of tumor necrosis factor-related apoptosis-inducing ligand is associated with favorable ovarian cancer survival. Clin. Cancer Res. 9: 762-766.

85) Inoue, H., Shiraki, K., Yamanaka, T., Ohmori, S., Sakai, T., Deguchi, M., Okano, H., Murata, K., Sugimoto, K. and Nakano, T. (2002). Functional expression of tumor necrosis factor-related apoptosis-inducing ligand in human colonic adenocarcinoma cells. Lab. Invest. 82: 1111-1119.

86) Shin, E. C., Ahn, J. M., Kim, C. H., Choi, Y., Ahn, Y. S., Kim, H., Kim, S. J. and Park, J. H. (2001). IFN-gamma induces cell death in human hepatoma cells through a TRAIL/death receptor-mediated apoptotic pathway. Int. J. Cancer. 93: 262-268.

87) El-Deiry, W. S. (2001). Insights into cancer therapeutic design based on p53 and TRAIL receptor signaling. Cell Death Differ. 8: 1066-1075.

88) Walczak, H. and Krammer, P. H. (2000). The CD95 (APO-1/Fas) and the TRAIL (APO-2L) apoptosis systems. Exp. Cell. Res. 256: 58-66.

89) Laurenzi, L., Natoli, S., Di Filippo, F., Calamaro, A., Centulio, F., Anza, M., Cavaliere, F., Marcelli, M. E., Garinei, R. and Arcuri, E. (2004). Systemic and haemodynamic toxicity after isolated limb perfusion (ILP) with TNF-alpha. J. Exp. Clin Cancer Res. 23: 225-231.

90) Mundt, A. J., Vijayakumar, S., Nemunaitis, J., Sandler, A., Schwartz, H., Hanna, N., Peabody, T., Senzer, N., Chu, K., Rasmussen, C. S., Kessler, P. D., Rasmussen, H. S., Warso, M., Kufe, D. W., Gupta, T. D. and Weichselbaum, R. R. (2004). A Phase I trial of TNFerade biologic in patients with soft tissue sarcoma in the extremities. Clin. Cancer Res. 10: 5747-5753.

91) Noorda, E. M., Vrouenraets, B. C., Nieweg, O. E., van Geel, B. N., Eggermont, A. M. and Kroon, B. B. (2004). Isolated limb perfusion for unresectable melanoma of the extremities. Arch. Surg. 139: 1237-1242.

92) Bartlett, D. L., Libutti, S. K., Figg, W. D., Fraker, D. L. and Alexander, H. R. (2001). Isolated hepatic perfusion for unresectable hepatic metastases from colorectal cancer. Surgery. 129: 176-187.

93) LeBlanc, H., Lawrence, D., Varfolomeev, E., Totpal, K., Morlan, J., Schow, P., Fong, S., Schwall, R., Sinicropi, D. and Ashkenazi, A. (2002). Tumor-cell resistance to death receptor--induced apoptosis through mutational inactivation of the proapoptotic Bcl-2 homolog Bax. Nat. Med. 8: 274-281.

94) Mitsiades, C. S., Treon, S. P., Mitsiades, N., Shima, Y., Richardson, P., Schlossman, R., Hideshima, T. and Anderson, K. C. (2001). TRAIL/Apo2L ligand selectively induces apoptosis and overcomes drug resistance in multiple myeloma: therapeutic applications. Blood. 98: 795-804.

95) Pollack, I. F., Erff, M. and Ashkenazi, A. (2001). Direct stimulation of apoptotic signaling by soluble Apo2l/tumor necrosis factorrelated apoptosis-inducing ligand leads to selective killing of glioma cells. Clin. Cancer Res. 7: 1362-1369.

96) Bhojani, M. S., Rossu, B. D. and Rehemtulla, A. (2003). TRAIL and anti-tumor responses. Cancer Biol. Ther. 2: S71-78.

97) Ehrhardt, H., Fulda, S., Schmid, I., Hiscott, J., Debatin, K. M. and Jeremias, I. (2003). TRAIL induced survival and proliferation in cancer cells resistant towards TRAIL-induced apoptosis mediated by NF-kappaB. Oncogene. 22: 3842-3852. 